\title{
Yellow bristle grass (Setaria pumila) germination biology
}

\author{
Claire A. Dowsett ${ }^{1, \star}$, Chris Buddenhagen ${ }^{1}$, Trevor K. James ${ }^{1}$ and Craig R. McGill ${ }^{2}$ \\ ${ }^{1}$ AgResearch, Ruakura Research Centre, Private Bag 3123, Hamilton 3240, New Zealand \\ ${ }^{2}$ Massey University, Private Bag 11222, Palmerston North 4442, New Zealand \\ ${ }^{*}$ Corresponding author: Claire.dowsett@agresearch.co.nz
}

\begin{abstract}
The presence of Setaria pumila in dairy pastures lowers feed quality and may cause grazing avoidance. More information is required about the germination biology of this weed to improve the effectiveness of control strategies. Base temperature and germination profile were determined on a thermo-gradient table. For emergence depth, seeds were buried at 0-50 $\mathrm{mm}$ and time to emerge recorded. Seed persistence was tracked at seven field sites over 5 years and in a laboratory-based controlled-ageing test. Base temperature for germination was $10.2^{\circ} \mathrm{C}$, germination was most rapid at $30-35^{\circ} \mathrm{C}$ and most numerous from $20-30^{\circ} \mathrm{C}$. Emergence occurred from $2-50 \mathrm{~mm}$ depth but mostly from $2-15 \mathrm{~mm}$. The controlledageing test indicated the seed was viable for $<3$ years. However, some Setaria pumila seed continued to germinate after 5 years of burial in all but the clay soil. Farmers should try to prevent this species from seeding for at least 5 years to reduce the seed bank. Soil inversion could promote dormancy and seed persistence. If followed by effective control, cultivation could stimulate germination and further reduce the seed bank.
\end{abstract}

Keywords Setaria pumila, yellow bristle grass, germination, seed persistence

\section{INTRODUCTION}

The summer annual weed yellow bristle grass (Setaria pumila) has a C4 photosynthetic pathway and is found to lower feed quality, reduce ryegrass-clover yield and cause grazing avoidance in dairy pastures in the North Island of New Zealand (Tozer et al. 2009). In pasture, infestations are managed with foliar applications of the herbicide fenoxaprop, pulling and digging, and by timing mowing to avoid seed spread. Setaria pumila seed survives passage through the rumen of stock so keeping stock out of infested fields during flowering and seed set also reduces spread (James 2011). In the Waikato region, germination normally occurs from midNovember and continues through to February, then flowering occurs approximately 6-8 weeks after germination. An average $S$. pumila plant produces 60 panicles, each containing between
60-200 (average 90) seeds (Forcella et al. 2000; Tozer et al. 2008; Tozer et al. 2009). Dieback occurs in autumn and this creates space in pasture for other weeds to colonise. In severe cases, complete pasture renewal maybe necessary.

Seed dispersal, longevity, germination and emergence are key factors that influence weed persistence and competitive ability (Forcella et al. 2000; Baskin \& Baskin 2001). Understanding the seed biology of $S$. pumila could provide important information to support effective (evidence-based) weed management (Forcella et al. 2000; Bradford 2002). Germination may be manipulated through land-management techniques which either promote germination or prevent it such as grazing intensity, irrigation and the use of tillage systems (Cardina et al. 2002; Chauhan \& Johnson 2010; Scherner et al. 2016).

The aim of this study was to assess the 
persistence of seed in the soil seed-bank, the depth from which emergence is possible and the temperature range across which the seeds will germinate. Preliminary results of the persistence study were published by Dowsett \& James (2012) and this paper presents data for $S$. pumila from the final 2 years of the study.

\section{MATERIALS AND METHODS \\ Preparation of seed}

Setaria pumila plants were collected from a farm in Paterangi, south of Hamilton, New Zealand in 2007 and were propagated for seed in a glasshouse. This seed was used in these studies. The viability of this seed was assessed by germinating four replicates of 50 seeds on steelblue seed-germination blotters (Anchor Paper Company, St. Paul, Minnesota) at alternating temperatures of $20^{\circ} \mathrm{C}$ for $16 \mathrm{~h}$ with no light and $30^{\circ} \mathrm{C}$ for $8 \mathrm{~h}$ with light, similar conditions to those used for two other Setaria species in the ISTA Rules (ISTA 2015). A seedling was scored as normal when it showed: (1) a well-developed and healthy primary root; (2) a coleoptile free of splits at the base or less than one-third of the coleoptile length if split from the top; and (3) an intact primary leaf emerging through the coleoptile (ISTA 2003).

\section{Depth of emergence}

Depth of emergence was investigated following James et al. (2016). Forty PVC columns (150$\mathrm{mm}$ tall and $100 \mathrm{~mm}$ in diameter) were partially filled to depths of $150,148,145,140,135,130$, $125,115,105,100 \mathrm{~mm}$ with Horotiu silt loam soil. Fifty seeds were scattered at that depth and the columns filled to the top with the same soil. There were four replicate columns for each depth. The columns were maintained in a HortiMax ${ }^{\circledR}$ controlled glasshouse between $15^{\circ} \mathrm{C}$ and $25^{\circ} \mathrm{C}$ and both top- and sub-irrigated to keep the soil moist. Emergence of seedlings was recorded weekly for 6 weeks. Mean germination rates and standard deviation are given for all depths in Figure 1.

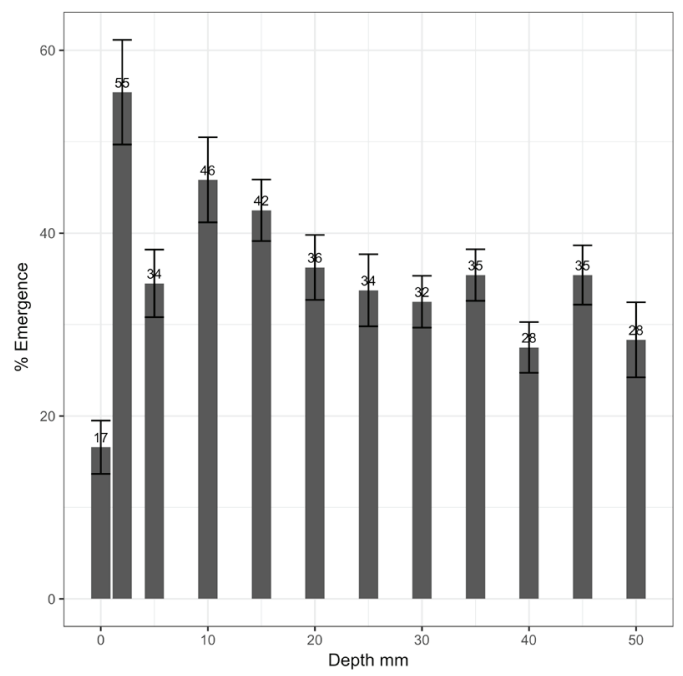

Figure 1 Emergence of Setaria pumila seedlings from seed buried in experimental soil columns for 42 days (error bars are the standard error of the mean, numbers above the bars are means).

\section{Buried-seed study}

Eight seed burial sites in different soils were selected across New Zealand, the preliminary results for which are reported previously (Dowsett \& James 2012). The soils at these sites were classified according to the European Soil Map fineness standard using the $\mathrm{R}$ package soil texture version 1.4.5 (Moeys 2018). These were: Wairua clay soil (very-fine) at Jordan Valley, Northland; Horotiu silt loam soil (medium) at Tamahere, Waikato; Ohinepanea loamy sand soil (coarse) at Blennerhasset, Bay of Plenty; Matawhero clay loam soil (medium) at Manutuke, Poverty Bay; Te Mata Mangateretere silt loam soil on clay (medium) at Havelock North, Hawke's Bay; Kairanga fine sandy loam soil (medium) at Palmerston North, Manawatu; Sherry sand/ sandy loam soil (medium) at Motueka, Tasman; and Taitapu silt loam soil (medium) at Lincoln, Canterbury. As described by Dowsett \& James (2012), 30 seed burial columns (250 mm lengths of perforated, $60 \mathrm{~mm}$ diameter plastic drainpipe) were prepared for each of eight sites. They were filled with local soil and buried with their tops 
flush with the soil surface. Seed bags with 200 yellow bristle grass seeds were placed in the columns at depths of $50 \mathrm{~mm}$ and $200 \mathrm{~mm}$ from the soil surface. Five replicate columns were removed from each site, in early summer each year for 5 years. Seeds from each bag were grown out in glasshouses at Ruakura Research Centre, Hamilton. A polystyrene seed tray was half filled with potting mix and topped with a layer of weed mat. The contents of each bag were mixed evenly through $1 \mathrm{~kg}$ of seed-raising mix (Daltons, Matamata, New Zealand) and spread out on top of the weed mat to a depth of $10 \mathrm{~mm}$. The seed trays were maintained at ambient temperature and kept moist. Germination was recorded following emergence of seedlings after 4 weeks.

Genstat software was used to carry out a three-way ANOVA of germination rate (multiyear analysis) for the factors (Year, Location and Depth) and blocked by Column, which included both depths within a column. Mean rates for the two depths were plotted for each year using the R-package software ggplot2.

\section{Controlled ageing test}

Seed longevity was assessed through comparative seed-longevity testing in the laboratory (controlled ageing test, CAT) brought about by storing hydrated seed at high humidity and temperature (Newton et al. 2009). To ensure seed were at equilibrium seed moisture content following storage conditions, 60 open glass Petri dishes with 50 seeds each were kept in a controlled environment using a lithium chloride solution as prescribed in Newton et al (2009) at $20 \pm 1^{\circ} \mathrm{C}$ with $47 \%$ relative humidity (RH) for 14 days. Equilibrium was reached when seed weight remained constant. Once equilibrium had been reached, the temperature and humidity of the seed were increased to $45 \pm 1^{\circ} \mathrm{C}$ and $60 \% \mathrm{RH}$. Four of these glass Petri dishes were randomly sampled at $0,1,2,3,5,6,8,10,15,20,25,30$, 50,75 and 100 days. Seed viability was assessed through a germination test where seed were placed between paper towels wetted with water and inserted into plastic ziplock bags. These were held in a germination room at $25^{\circ} \mathrm{C}$ for $16 \mathrm{~h}$ dark and $30^{\circ} \mathrm{C}$ for $8 \mathrm{~h}$ light. Radical emergence was scored over a 6-week period (ISTA 2015).

Data were analysed based on non-linear regression using the R-package (drc 3.0-1) with a three-parameter model (Ritz \& Streibig 2005; Ritz et al. 2013; Ritz et al. 2015), where $b=$ slope at $\mathrm{T}_{50}, \mathrm{~d}=$ =upper limit, $\mathrm{e}=$ intercept at $\mathrm{T}_{90}$. The time to achieve an effective kill of $50 \%\left(\mathrm{~T}_{50}\right)$ and $90 \%\left(\mathrm{~T}_{90}\right)$ under this temperature and humidity regime was estimated using the ED function (also in the drc package) for the three-parameter model just described.

\section{Base temperature and germination profile}

To determine the germination profile for the $S$. pumila seed lot, a Grant Thermogradient Plate (Grant Instruments Limited, Cambridge, United Kingdom) was set to run a one-way gradient from 7 to $35^{\circ} \mathrm{C}$. Minimum and maximum temperatures were verified by measuring the temperature on the germination blotters manually with a thermometer. A layer of K-22 Kimpak $^{\circledast}$ blotter (Anchor Paper Company, St. Paul, Minnesota) soaked in water was placed on the table surface under the same two layers of steel-blue seed germination blotters used for the earlier seed germination assessment, also soaked in water. The table was located in a laboratory and received natural light. Four replicates with 45 seeds per replicate were placed at $1^{\circ} \mathrm{C}$ increments. Germination was scored daily, and recorded when radicles emerged. Seed was left in place until normal seedling development could be measured. After 85 days, the table was set to $25^{\circ} \mathrm{C}$ and remaining seed allowed to germinate. The base temperature is the $\mathrm{x}$-intercept for germination $\left(\mathrm{T}_{\mathrm{b}}\right)$ in a plot of $1 /$ $\mathrm{T}_{50}$ against germination temperature (Coolbear et al. 1984) where $\mathrm{T}_{50}$ is defined as the time taken from sowing for the median seed to germinate. Mathematically $\mathrm{T}_{50}$ is defined as:

$$
\mathrm{T}_{50}=\mathrm{t}_{\mathrm{i}}+\left[\frac{\mathrm{N}+1}{\frac{2}{\left(\mathrm{n}_{\mathrm{j}}-\mathrm{n}_{\mathrm{i}}\right)}}\right] \times\left(\mathrm{t}_{\mathrm{j}}-\mathrm{t}_{\mathrm{i}}\right)
$$

where $n_{i}$ and $n_{J}$ are cumulative germination 
counts at adjacent counting times $t_{i}$ and $t_{j}$, where $\mathrm{n}_{\mathrm{i}}<(\mathrm{N}+1) / 2<\mathrm{n}_{\mathrm{J}}$ and $\mathrm{N}$ is the total number of seeds that germinated. This assumes the following thermal-time relationship:

$\left(\mathrm{T}-\mathrm{T}_{\mathrm{b}}\right) \times \mathrm{t}=\mathrm{K}$

where $t$ is the time to radicle emergence, $T$ is the ambient temperature, $\mathrm{T}_{\mathrm{b}}$ is the base temperature and $\mathrm{K}$ is the thermal time constant.

\section{RESULTS}

\section{Seed quality and depth of emergence}

The S. pumila seed had $83 \%$ normal germination. Mean germination rates and standard deviation are given for all depths in Figure 1. Seeds on the soil surface experienced the lowest levels of emergence, while germination was highest at depths of $2 \mathrm{~mm}$ (Fig. 1). Germination/emergence rates remained high for all the depths tested, it was higher between 2 and $15 \mathrm{~mm}$. Mean germination rates never dropped below 28\% even at the deepest depth tested $(50 \mathrm{~mm})$.

\section{Buried-seed study}

Results from the seed burial study indicated that viable seed persisted for five years at both depths tested, and depletion of the seed bank was more rapid at the shallower level. The percent germination observed ranged between $0-46 \%$ (mean 10\%), when buried at $200 \mathrm{~mm}$, and was 0-32\% (mean 5\%) at 50-mm depth (Fig. 2). There was no replication within some of the soil fineness categories (most sites had medium soil fineness). Estimates of variation are from within-site replication of experimental columns for coarse and very fine soils. The lowest mean (and standard deviation) for emergence rates in year 5 were observed in coarse $3 \%( \pm 4)$, and very fine (clay) soils $0 \%(0)$. Germination rates of $6 \%$ $( \pm 9)$ and $27 \%( \pm 10)$ were recorded in medium and fine soil respectively. Very low average or zero germination rates were found at five of the eight sites in year five; Northland and Poverty Bay had zero germination, and Tasman (2\%), Manawatu (1\%), Bay of Plenty (3\%). Higher rates were found at Canterbury (18\%), Hawkes Bay
(27\%), and Waikato (11\%). Seed persisted at both depths for at least 5 years (Fig. 2) and across soil textures, except in fine clay soils. In the multiyear ANOVA tests, all the examined factors were significant, but the most consistent observation is that seed persisted longer at the greater depth.

\section{Controlled ageing test}

Controlled ageing showed a decline in percent germination until 15 days when seed germination reached zero, and no further germination was detected at later sampling periods (Fig. 3). The P50 was estimated at 6.8 days (standard error 0.30 days), and $\mathrm{P}_{90}$ at 13.3 days (1.03 days).

\section{Germination temperature range and percent germination}

The lowest germination (5\%) was observed at $11^{\circ} \mathrm{C}$ (Fig. 4), and no germination was observed between 7 and $10^{\circ} \mathrm{C}$. The maximum radicle emergence/normal germination of $87 \%$ was reached at $25^{\circ} \mathrm{C}$. There was no significant difference in radicle emergence between $20^{\circ} \mathrm{C}$ and $30^{\circ} \mathrm{C}$ (Chi-Square $=104.9206, \mathrm{P}<0.0001$ for radicle emergence and Chi-Square $=104.3514, \mathrm{P}<0.0001$ for normal germination). At temperatures below $20^{\circ} \mathrm{C}$ and above $30^{\circ} \mathrm{C}$, both radicle emergence and germination were significantly lower than those between $22^{\circ} \mathrm{C}$ and $26^{\circ} \mathrm{C}$. Normal germination percentage declined at higher temperatures with, for example, germination at $30^{\circ} \mathrm{C}(74 \%)$ being significantly higher than that at $35^{\circ} \mathrm{C}(42 \%)$. Mould was observed on some of the seeds at higher temperatures. A cut test at the end of the trial indicated that seed remaining on the temperature gradient table was potentially viable indicating that seed death was not the cause of the reduced germination at higher temperatures.

The regression analysis of $1 / \mathrm{T}_{50}$ against germination temperature gave a regression line of $y=0.0005 x+-0.0051 ; R^{2}=0.9479$; suggesting a base temperature of $10.2^{\circ} \mathrm{C}$ for this S. pumila seed lot (Fig. 4). 


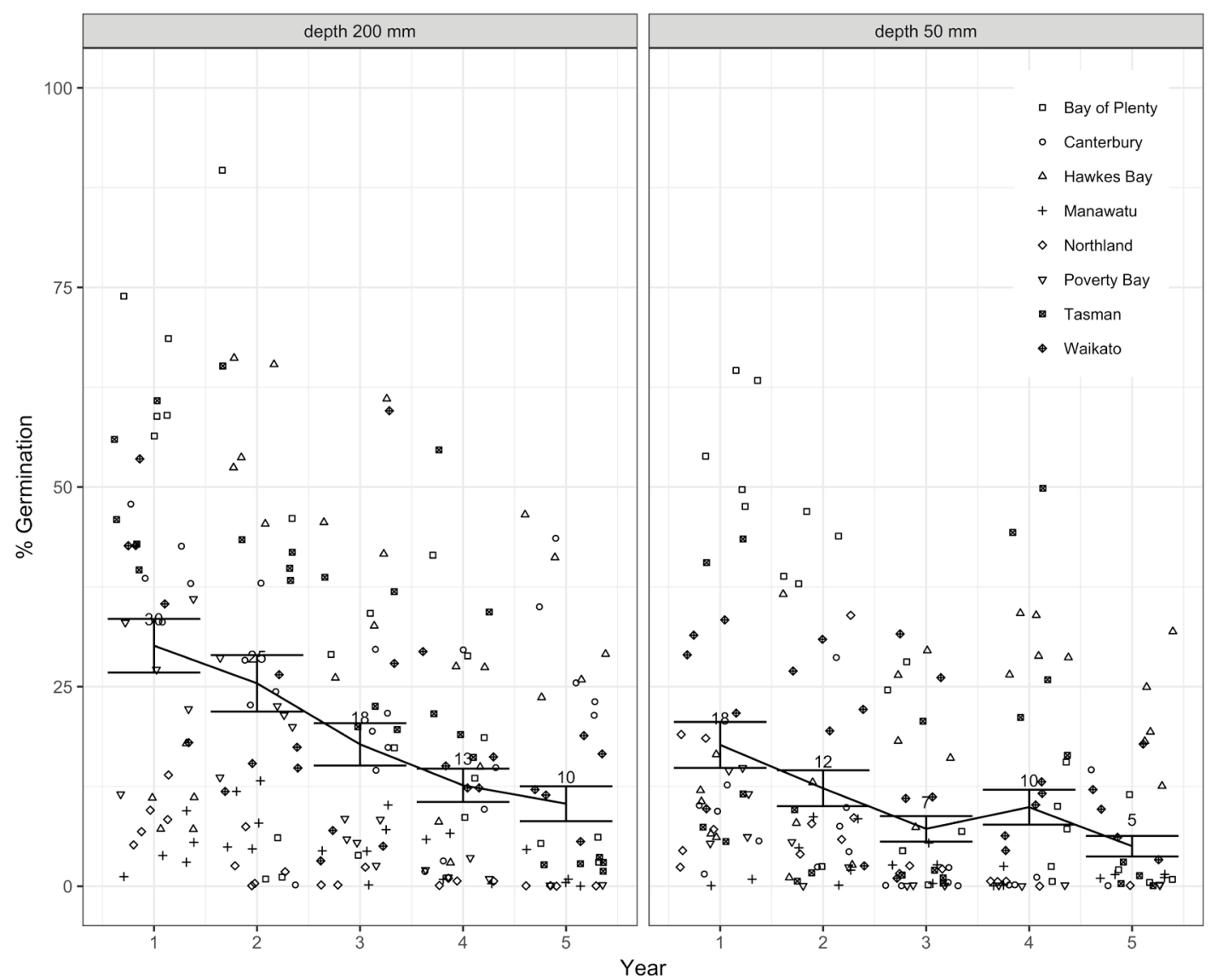

Figure 2 Germination of Setaria pumila seeds remaining after burial for 5 years at eight sites at depths of 50 or $200 \mathrm{~mm}$ at sites throughout New Zealand (error bars are the standard error of the mean, numbers above bars are means).

\section{DISCUSSION}

\section{Seed quality and depth of emergence}

Under the ideal conditions of the germination test $83 \%$ of the seed germinated. There was some decline in emergence with depth though percent germination remained high at the deepest depth we tested ( $50 \mathrm{~mm} ; 28 \%$ germination). As such, plants in the field are expected to establish from seeds buried at this depth. These results raise a key question relating to the feasibility of using a soil-inversion process (such as ploughing) to bury seeds to a depth below which S. pumila plants cannot emerge. Soil inversion in New Zealand ploughing systems buries seed to 150 $\mathrm{mm}$. The relationship between seed size and the ability to emerge from depth is well established, as small seeds have less reserves to emerge from depth (James et al. 2002). Setaria pumila has a relatively large seed when compared with those reported for other temperate $\mathrm{C} 4$ species, with a thousand seed mass of $2.74 \mathrm{~g}$ versus an average of $1.13 \mathrm{~g}$ (Csontos \& Kalapos 2013). The much larger seed of Panicum miliaceum, $4.269 \mathrm{~g}$, is capable of emergence from as much as $150 \mathrm{~mm}$ (James et al. 2011), though the similar or slightly smaller seed of Echinochloa crus-galli, $2.204 \mathrm{~g}$, has been shown to emerge from $100 \mathrm{~mm}$ (Ogg \& Dawson 1984). 


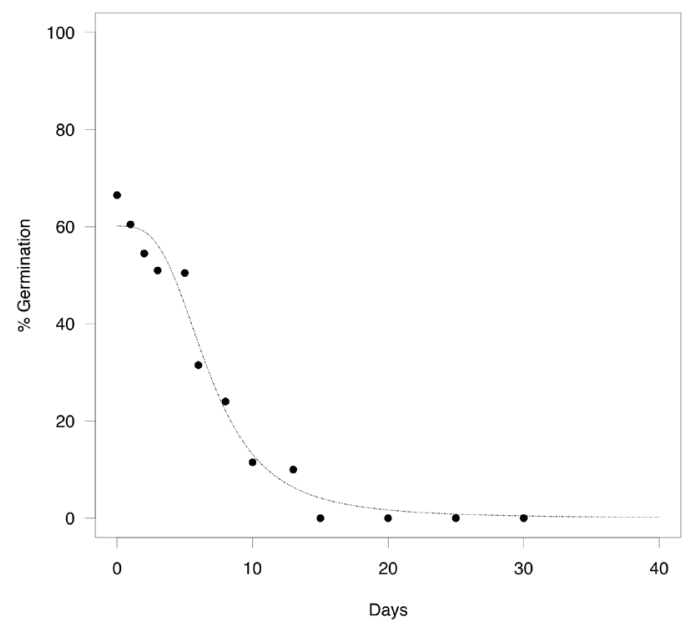

Figure 3 Controllead ageing test germination rates at intervals up to 100 days but no germination was observed after 15 days. The fitted line is based on a non-linear regression using the R-package (drc 3.0-1) with a threeparameter model. $\mathrm{P}_{50}$ (time to $50 \%$ decline in seed persistence) and $\mathrm{P}_{90}$ (time to $90 \%$ decline in seed persistence) were calculated at 6.8 and 13.3 days respectively.

\section{Seed burial}

Seed persistence has been observed in Setaria spp. and in related genera (Dekker 2003), and there is often an interplay between seed depth and persistence (Baskin \& Baskin 2001). The length of time that $S$. pumila seeds are able to survive in the soil is variable and generally increases with burial depth. The maximum period of survival in the soil varies dependent on environmental factors though Dekker (2003) suggests typically, 13 years; and at maximum, 30 years. As such soil inversion as discussed above may not be suitable for the management of the S. pumila seed bank (Cardina et al. 2002; Scherner et al. 2016). Seed buried in the current field study survived at least 5 years, with higher rates of survival from seed buried below $200 \mathrm{~mm}$ than seed nearer the soil surface. Villiers (1974) suggested that the low metabolic rate experienced by dormant seeds in the soil seed bank enables seed, after hydration, to repair damage and detoxify. Therefore, wet-

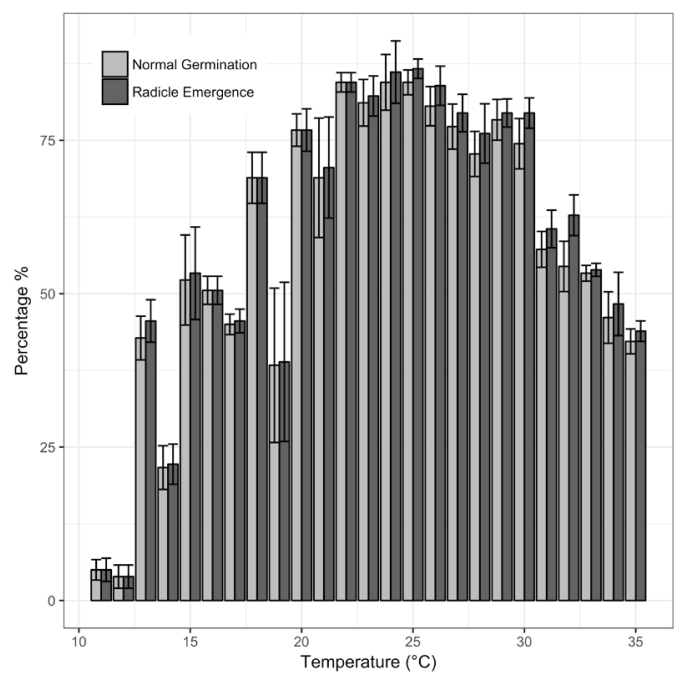

Figure 4 Radicle emergence (\%) and normal germination (\%) of S. pumila seed after 85 days on a Grant one-way thermogradient plate using germination temperatures of 7 to $35^{\circ} \mathrm{C}$ (error bars are the standard error of the mean).

dry cycling experienced in the soil seed bank might promote persistence. It is to be expected that a variable environment in the field (and consequently soil seed bank depletion as a result of seed germination and death) could vary with depth. The relative importance of these two factors is difficult to determine from this study but some seed survived at both the depths tested to at least year five. Although none of the sites had zero germination in year 4 , by year 5 , two sites had zero germination, and three sites had germination $<3 \%$ for both depths. These results indicate that the soil seed bank is likely to be largely depleted in most soil types if seeding can be prevented for five years although site-to-site variation was high, and germination was over $10 \%$ at the remaining three sites in year five. One site had high levels of clay and no seed survived after 5 years (it also had the lowest germination in year 4). This rapid disappearance of the seed from clay soil has been observed previously by 
James et al. (2010). Soil seed-bank decay may be faster in clay soils than in lighter soils, especially for a variety of grass species (Dowsett \& James 2012) but more data are needed to confirm this. If this observation were to be consistent at all sites with high clay content then farmers with clay soils could have a better chance of depleting the seed in the soil seed bank than those with lighter soils, provided seeding can be prevented.

\section{Controlled aging}

Following the comprehensive study performed by Long et al (2008), the CAT $\mathrm{P}_{50}$ value may be converted into a rough prediction of field persistence. Species with low CAT $\mathrm{P}_{50}$ (110) values tended to have relatively short seed persistence, those with higher $\mathrm{P}_{50}$ values $(>10)$ had longer persistence. The decline in germination observed during the controlledageing test indicated the seed should be short lived, i.e. survives less than 3 years in the environment (Long et al. 2008; Dowsett et al. 2012); our model estimated a $P_{90}$ of 13.3 days. In other words, $10 \%$ of seed is likely to continue to persist in the environment for longer. Compared with C3 species, C4 plants respond differently to the heat and humidity based controlled aging test we used (Qi \& Redmann 1993; Newton et al. 2009). On average, germination rates of $\mathrm{C} 4$ grasses are higher than that of $\mathrm{C} 3$, and also C4 grasses, on average, age more slowly than expected under such conditions (Zhang et al. 2014; Satyanti et al. 2018). Larger seeds are often found to have shorter persistence in the seedbank than smaller seeds (Masin et al. 2006; Satyanti et al. 2018) though our study shows that S. pumila survives in the seedbank for longer than 3 years. Setaria spp. as a genus has been shown to persist for longer when buried at depth (Dekker 2003).

\section{Seed germination}

Germination of $S$. pumila was most rapid at $30-35^{\circ} \mathrm{C}$; but the percentage normal germination was significantly lower than that between $20^{\circ} \mathrm{C}$ and $30^{\circ} \mathrm{C}$. Dormancy has been reported in S. pumila seed (Baskin et al., 1996). Masin et al. (2006) report dormancy cycling in Setaria glauca where seeds germinated in spring but showed little or no germination in summer. Dekker (2003) suggests that temperatures of $30^{\circ} \mathrm{C}$ or greater can induce secondary dormancy ("summer" dormancy) in Setaria spp. (Dekker 2003). These observations are consistent with the low germination of seed observed at the higher temperatures on the temperature gradient table and that secondary dormancy may have occurred at higher temperatures on the temperature gradient table.

The calculated base temperature of $10.2^{\circ} \mathrm{C}$ is similar to that found for five Setaria lutescens biotypes (a known synonym for $S$. pumila). There was no germination at $10^{\circ} \mathrm{C}$ or $40^{\circ} \mathrm{C}$, but some between $15^{\circ} \mathrm{C}$ and $35^{\circ} \mathrm{C}$ and the highest germination was observed between $20-25^{\circ} \mathrm{C}$ (Norris \& Schoner 1980). A Climex model (which describes the response of a species to climate) indicated that the inferred optimal air temperature for population growth of $S$. pumila in New Zealand is between $18-24^{\circ} \mathrm{C}$ (Lamoureaux \& Bourdôt 2014). This same model indicated that at temperatures below $8^{\circ} \mathrm{C}$ and above $35^{\circ} \mathrm{C}, \mathrm{S}$. pumila would experience levels of stress unfavourable for growth. In the case of the soil seed bank, however, soil temperature has a greater effect on seed germination and persistence than air temperature (which is more important for growth of the plant). The annual average temperatures right across New Zealand at a soil depth of $10 \mathrm{~cm}$ easily exceed the base temperature for germination between November and March. Average soil temperatures in New Zealand do not reach the ideal germination range of between $20-30^{\circ} \mathrm{C}$ although temperatures of $18-20^{\circ} \mathrm{C}$ are common for all the North Island and most of the upper South Island during December, January and February. Interestingly, areas where soil temperature is higher (e.g. Northland and Poverty Bay) (NIWA 1981-2010) are also the areas where lower seed persistence was observed during the burial study.

In summary, these studies have determined that seed of Setaria pumila readily germinates from depths of up to $50 \mathrm{~mm}$ and more. This seed may persist for at least 3 years in the soil; however, 
persistence is likely to be dependent on factors such as soil type, soil temperature and depth of burial. After 5 years, seed persistence could be as much as $46 \%$ or as little as $0 \%$ depending upon these conditions. Farmers should try to prevent seeding for at least 5 years to reduce abundance in the seed bank. Soil inversion could promote dormancy and seed persistence and, therefore, is not recommended. Cultivation will stimulate germination and, if followed by effective control using herbicides or shallow tillage, it should further reduce the seed bank.

\section{ACKNOWLEDGEMENTS}

This study was funded by The Foundation for Arable Research (FAR) and The Yellow Bristle Grass Action Group. We thank Mike Parker (FAR) for assistance with the buried seed study. Thanks also go to Erin Carney, Kris Krammer-Walter and University of Waikato BScTech students, Emily Hunt, Yasmin Lovell, Jordan Cooper, Katherine Pellow and Francis Williamson for their technical assistance.

\section{REFERENCES}

Baskin CC, Baskin J 2001. Seeds Ecology, Biogeography, and Evolution of Dormancy and Germination. London, Academic Press.

Bradford KJ 2002. Applications of hydrothermal time to quantifying and modeling seed germination and dormancy. Weed Science 50(2): 248-260.

Cardina J, Herms CP, Doohan DJ 2002. Crop rotation and tillage system effects on weed seedbanks. Weed Science 50(4): 448-460.

Chauhan BS, Johnson DE 2010. The Role of Seed Ecology in Improving Weed Management Strategies in the Tropics. Advances in Agronomy. Metro Manila, Philippines, Elsevier Inc. Pp. 221-262.

Coolbear P, Francis A, Grierson D 1984. The effect of low temperature pre-sowing treatment on the germination performance and membrane integrity of artificially aged tomato seeds. Journal of Experimental Botany 35: 16091617.

Csontos P, Kalapos T 2013. More lightweight and isodiametric seeds for $\mathrm{C} 4$ than for $\mathrm{C} 3$ grasses are associated with preference for open habitats of $\mathrm{C} 4$ grasses in a temperate flora. Grass and Forage Science 68(3): 408-417.

Dekker J 2003. The foxtail (Setaria) speciesgroup. Weed Science 51(5): 641-656.

Dowsett C, James T, Trivedi P 2012. Adaption of a technique for the accelerated ageing of weed seeds to evaluate their longevity. New Zealand Plant Protection 65: 69-73.

Dowsett CA, James TK 2012. Seed longevity of cropping weeds in soils. Agronomy New Zealand 42: 163-170.

Forcella F, Colbach N, Kegode GO 2000. Estimating seed production of three Setaria species in row crops. Weed Science 48(4): 436-444.

ISTA 2003. ISTA Handbook on Seedling Evaluation. Bassersdorf, CH-Switzerland, International Seed Testing Association.

ISTA 2015. International Rules for Seed Testing. CH-8303 Bassersdorf Switzerland, ISTA Secretariat.

James TK 2011. Yellow Bristle Grass - the ute guide 3rd edition. MPI ed. Wellington. New Zealand.

James TK, Rahman A, Trivedi P 2010. Germination of seed from five broadleaf weeds after burial for up to 28 years in two soils. New Zealand Plant Protection 63: 8489.

James TK, Rahman A, Webster T, Waller J 2002. Emergence of weeds as affected by vertical seed distribution in arable soils. New Zealand Plant Protection 55: 213-217.

James TK, Rahman A, McGill CR, Trivedi PD 2011. Biology and survival of broom corn millet (Panicum miliaceum) seed. New Zealand Plant Protection 64: 142-148.

James TK, Rahman A, Trolove MR, Dowsett CA 2016. Seed germination characteristics and control options for Noogoora bur (Xanthium strumarium) in commercial maize production. New Zealand Plant Protection 69: 270-277.

Long RL, Panetta FD, Steadman KJ 2008. Seed persistence in the field maybe predicted by 
laboratory controlled ageing. Weed Science 56: 523-528.

Masin R, Zuin MC, Otto S, Zanin G 2006. Seed longevity and dormancy of four summer annual grass weeds in turf. Weed Research 46: 362-370.

Moeys J 2018. soiltexture: Functions for Soil Texture Plot, Classification and Transformation. $\mathrm{R}$ package version 1.4.5. https://CRAN.R-project.org/ package $=$ soiltexture

Newton R, Hay F, Probert R 2009. Protocol for comparative seed longevity testing http://www.kew.org/sites/default/files/1_ ppcont_014163_Protocol\%20for\%20 comparative $\% 20$ seed $\% 20$ longevity $\% 20$ testing_0.pdf

NIWA 1981-2010. Mean $10 \mathrm{~cm}$ earth temperature $\left({ }^{\circ} \mathrm{C}\right)$, updated 04.04.2018: https://www. niwa.co.nz/education-and-training/schools/ resources/climate/earthtemp

Ogg AG, Dawson JH 1984. Time of emergence of eight weed species. Weed Science 32(3): 327-335.

Qi MQ, Redmann RE 1993. Seed germination and seedling survival of C3 and C4 grasses under water stress. Journal of Arid Environments 24(3): 277-285.

Ritz C, Streibig JC 2005. Bioassay analysis using R. Journal of statistical software 12: 1-22.

Ritz C, Pipper CB, Streibig JC 2013. Analysis of germination data from agricultural experiments. European Journal of Agronomy 45: 1-6.

Ritz C, Baty F, Streibig JC, Gerhard D 2015. Dose-response analysis using R. PloS one 10: e0146021.

Satyanti A, Nicotra AB, Merkling T, Guja LK 2018. Seed mass and elevation explain variation in seed longevity of Australian alpine species. Seed Science Research: 1-13.

Scherner A, Melander B, Kudsk P 2016. Vertical distribution and composition of weed seeds within the plough layer after eleven years of contrasting crop rotation and tillage schemes. Soil and Tillage Research 161: 135-142.

Tozer KN, James TK, Cameron CA 2008.
Botanical and management factors associated with Setaria pumila abundance: Implications for pasture management. New Zealand Plant Protection 61: 121-126.

Tozer KN, James TK, Rahman A 2009. Yellow bristle grass; a recent weed incursion in Waikato dairy pastures. New Zealand Grassland Association 71: 39-42.

Villiers T 1974. Seed aging: chromosome stability and extended viability of seeds stored fully imbided. Plant Physiology 53(6): 875-878.

Zhang H, Yu Q, Huang Y, Zheng W, Tian Y, Song Y, Li G, Zhou D 2014. Germination shifts of $\mathrm{C} 3$ and $\mathrm{C} 4$ species under simulated global warming scenario. PLoS ONE 9(8): e105139. 